\title{
Enhanced liver fibrosis score as a predictive marker for hepatocellular carcinoma development after hepatitis $\mathbf{C}$ virus eradication
}

\author{
TOSHIHIRO KAWAGUCHI ${ }^{1,2}$, TATSUYA IDE ${ }^{1}$, KEISUKE AMANO ${ }^{1}$, TERUKO ARINAGA-HINO $^{1}$, \\ REIICHIRO KUWAHARA ${ }^{1}$, TOMOYA SANO ${ }^{1}$, SHIRACHI MIKI $^{3}$, NAOFUMI ONO ${ }^{4}$ and TAKUJI TORIMURA ${ }^{1}$ \\ ${ }^{1}$ Division of Gastroenterology, Department of Medicine, Kurume University School of Medicine, Kurume, Fukuoka 830-0011; \\ ${ }^{2}$ Social Insurance Tagawa Hospital, Tagawa, Fukuoka 826-0023; ${ }^{3}$ Chikugo City Hospital, Chikugo, Fukuoka 833-0041; \\ ${ }^{4}$ Yame General Hospital, Yame, Fukuoka 834-0034, Japan
}

Received January 17, 2021; Accepted July 7, 2021

DOI: $10.3892 / \mathrm{mco} .2021 .2377$

\begin{abstract}
Advanced liver fibrosis is the most important risk factor for hepatocellular carcinoma (HCC) development after achieving sustained virological response (SVR) by direct-acting antiviral (DAA) treatment in patients with chronic hepatitis C. Wisteria floribunda agglutinin-positive Mac-2-binding protein (M2BPGi), enhanced liver fibrosis (ELF) score, type IV collagen and fibrosis-4 (FIB-4) index have been reported as non-invasive biomarkers for liver fibrosis. In the present study, the possibility of using fibrosis biomarkers and other parameters to predict the development of HCC was evaluated. A total of 743 patients infected with hepatitis $C$ virus who achieved SVR by using DAA were retrospectively enrolled. Of these, 122 patients whose blood samples were stored were selected. The aforementioned four fibrosis biomarkers were analyzed at baseline, at the end of treatment (EOT) and at post-treatment week 24 (PTW24). Tumor markers and laboratory tests were also analyzed. The baseline/EOT/PTW24 values for each fibrosis biomarker were as follows: ELF score: 11.5 $\pm 1.2 / 10.8 \pm 1.1 / 10.4 \pm 1.0$; type IV collagen: $213 \pm 85 / 190 \pm 67 / 174 \pm 55 \mathrm{ng} / \mathrm{ml}$; M2BPGi: 4.8 $\pm 3.5 / 2.7 \pm 2.0 / 2.2 \pm 1.8$; and FIB-4 index: 5.31 $\pm 3.82 / 4.36 \pm$ 2.79/4.24 \pm 3.09 . Of the 122 patients, 23 developed HCC. A high
\end{abstract}

Correspondence to: Dr Toshihiro Kawaguchi, Division of Gastroenterology, Department of Medicine, Kurume University School of Medicine, 67 Asahi-machi, Kurume, Fukuoka 830-0011, Japan

E-mail:kawaguchi_toshihiro@med.kurume-u.ac.jp

Abbreviations: AFP, $\alpha$-fetoprotein; DAA, direct-acting antiviral; ELF score, enhanced liver fibrosis score; FIB-4 index, fibrosis-4 index; HCC, hepatocellular carcinoma; M2BPGi, Wisteria floribunda agglutinin-positive Mac-2-binding protein; SVR, sustained virological response

Key words: hepatocellular carcinoma, chronic hepatitis C, sustained virological response, direct-acting antiviral, enhanced liver fibrosis score baseline ELF score $(\mathrm{P}=0.0264), \mathrm{PTW} 24 \mathrm{ELF}$ score $(\mathrm{P}=0.0003)$, PTW24 $\alpha$-fetoprotein level $(\mathrm{P}=0.0133)$, baseline FIB-4 index $(\mathrm{P}=0.0451)$ and low baseline prothrombin time $(\mathrm{P}=0.0455)$ were risk factors for HCC development based on univariate analyses. Based on the multivariate analysis, a high PTW24 ELF score was the only risk factor for HCC development $(\mathrm{P}=0.0035)$. The ELF score after DAA therapy was strongly associated with HCC development; therefore, it may be a useful marker for predicting $\mathrm{HCC}$.

\section{Introduction}

The advent of direct-acting antivirals (DAAs) revolutionized the treatment of hepatitis $\mathrm{C}$ virus (HCV) and high sustained virological response (SVR) rates may be achieved. The SVR rates were reported to be $89.9 \%$ with daclatasvir/asunaprevir (1), $95.8 \%$ with sofosbuvir/ribavirin (2), and $98.5 \%$ with sofosbuvir/ledipasvir (3). Accumulating evidence suggests that SVR with DAA treatment reduces the incidence of hepatocellular carcinoma (HCC) development (4-6). However, even after achieving SVR, some patients may develop HCC.

Advanced liver fibrosis was reported to be the most important risk factor for HCC development after SVR (7); therefore, evaluation of the degree of liver fibrosis is important. Regarding the evaluation of fibrosis, non-invasive methods (serum markers or transient elastography) were recently adopted instead of invasive liver biopsy. Representative fibrosis markers include type IV collagen (8), Wisteria floribunda agglutinin-positive Mac-2-binding protein (M2BPGi) (9), and fibrosis-4 (FIB-4) index $(10,11)$. On the other hand, an enhanced liver fibrosis (ELF) score composed of three liver fibrosis markers was developed to evaluate liver fibrosis (12). The ELF score was confirmed to be useful in patients with non-alcoholic fatty liver (13), primary biliary cholangitis/cirrhosis (14) and chronic hepatitis $C$ (15). It was recently reported that the ELF score was comparable with transient elastography in detecting advanced fibrosis $(\mathrm{F} \geq 3)$ in treatment-naïve patients with chronic HCV infection (16). In addition, the usefulness of ELF score as a predictor of HCC in the general population, 
particularly in predicting non-viral-related HCC, was previously reported (17).

Among these fibrosis markers, M2BPGi and FIB-4 index were reported to be useful markers for the risk of HCC development after HCV eradication $(18,19)$. On the other hand, other than fibrosis markers, $\alpha$-fetoprotein (AFP) was also reported to be useful for predicting $\mathrm{HCC}$ development after $\mathrm{HCV}$ eradication (20). However, to the best of our knowledge, there is no report confirming the usefulness of the ELF score for predicting $\mathrm{HCC}$ development after HCV eradication. The aim of the present study was to assess fibrosis markers, including ELF score, type IV collagen, M2BPGi and FIB-4 index, tumor markers, and biochemical tests associated with HCC development after viral eradication. The time course of the changes in fibrosis markers during and after DAA treatment was also examined.

\section{Materials and methods}

Subjects. Patients with chronic hepatitis C or liver cirrhosis from three hospitals in Japan (Kurume University Hospital, Yame General Hospital and Chikugo City Hospital) who were initiated on DAA therapy between October 2014 and September 2016 were selected. A total of 999 patients with chronic hepatitis $\mathrm{C}$ or liver cirrhosis were treated with DAA (daclatasvir plus asunaprevir, or ledipasvir plus sofosbuvir, or sofosbuvir plus ribavirin). SVR was achieved in 743 patients. The diagnosis of liver cirrhosis was comprehensively made based on biochemical test results, imaging findings and physical findings on a case-by-case basis. Among the patients who achieved SVR, 122 patients (50 male and 72 female patients, with a mean age \pm SD of $68.7 \pm 8.8$ years; range, $32-83$ years) whose blood samples were stored were enrolled (Fig. 1). All the patients were positive for $\mathrm{HCV}$ antibody as determined using chemiluminescence immunoassay (Architect ${ }^{\circledR}$; Abbott Japan Co., Ltd.). The HCV RNA levels were measured using a COBAS Taq Man test (Roche Diagnostics). Patients who had hepatitis B surface antigen, a history of HCC prior to DAA therapy, or developed HCC within 24 weeks after DAA therapy were excluded. Imaging surveillance (ultrasonography, computed tomography or magnetic resonance imaging) were undertaken every 3-6 months. Patients were followed up until HCC development or the last visit before October 2018. The mean observation period was 2.7 years after the initiation of DAA therapy. The present study was conducted according to the guidelines of the Declaration of Helsinki and was approved by the Ethics Committees of Kurume University School of Medicine (approval no. 14178), Yame General Hospital (approval no. 19-005), and Chikugo City Hospital (approval no. 2019-09). Written informed consent was obtained from all patients.

DAA therapy. The HCV treatment regimen of daclatasvir (60 mg once daily) plus asunaprevir (100 mg twice daily) for 24 weeks, or ledipasvir (90 mg) plus sofosbuvir (400 mg) for 12 weeks, was administered to patients with HCV genotype 1. Sofosbuvir (400 mg) plus ribavirin (weight-based dosing: $600 \mathrm{mg}$ daily for patients weighing $\leq 60 \mathrm{~kg}, 800 \mathrm{mg}$ daily for patients weighing $>60$ and $\leq 80 \mathrm{~kg}$, and $1,000 \mathrm{mg}$ daily for patients weighing $>80 \mathrm{~kg}$ ) for 12 weeks was administered to
Table I. Baseline characteristics of patients $(n=122)$ with chronic hepatitis $\mathrm{C}$.

\begin{tabular}{lc}
\hline Characteristics & Values \\
\hline Male, $\mathrm{n}(\%)$ & $50(41.0)$ \\
Cirrhosis/chronic hepatitis, $\mathrm{n}$ & $36 / 86$ \\
Genotype (1/2), $\mathrm{n}$ & $119 / 3$ \\
Treatment regimen, $\mathrm{n}$ & \\
Daclatasvir + asunaprevir & 113 \\
Ledipasvir + sofosbuvir & 6 \\
Sofosbuvir + ribavirin & 3 \\
Age (years) & $68.7 \pm 8.8$ \\
Aspartate aminotransferase (U/l) & $53 \pm 27$ \\
Alanine aminotransferase (U/l) & $51 \pm 36$ \\
Albumin (g/dl) & $3.9 \pm 0.4$ \\
Total bilirubin (mg/dl) & $0.8 \pm 0.3$ \\
Prothrombin time $(\%)$ & $91 \pm 16$ \\
Platelet count $\left(\mathrm{x} 10^{4} / \mu \mathrm{l}\right)$ & $12.4 \pm 5.0$ \\
$\alpha$-Fetoprotein $(\mathrm{ng} / \mathrm{ml})$ & $16.9 \pm 30.5$ \\
Des- $\gamma$-carboxy prothrombin $(\mathrm{mAU} / \mathrm{ml})$ & $20.4 \pm 18.1$ \\
\hline
\end{tabular}

Values are presented as mean $\pm \mathrm{SD}$, unless otherwise indicated.

patients with HCV genotype 2. SVR was defined as undetectable serum HCV RNA at 24 weeks after completing DAA therapy.

Liver fibrosis markers. Four fibrosis biomarkers (type IV collagen, M2BPGi, FIB-4 index and ELF score) were assessed in 122 patients. For all patients, the biomarkers were analyzed at baseline, at the end of treatment (EOT) and at post-treatment week 24 (PTW24). Type IV collagen was measured using a JCA-BM 8000 series automated immune analyzer (Japan Electron Optics Laboratory Ltd.). M2BPGi was measured using a HISCL-5000 (Sysmex Corporation). The FIB-4 index was calculated as follows: Age (years) $\mathrm{x}$ aspartate aminotransferase (AST; U/1)/platelet count $\left(10^{9} / 1\right) \mathrm{x}$ alanine aminotransferase (ALT; U/1) $)^{1 / 2}(10)$. The ELF score consists of three fibrosis markers: Hyaluronic acid (HA), amino-terminal propeptide of type III procollagen (PIIINP) and tissue inhibitor of metalloproteinase type-1 (TIMP-1). The ELF score (12) was measured using an ADVIA Center XP automated immunoanalyzer and calculated automatically using the following equation: $\mathrm{ELF}$ score $=2.278+0.851$ $\ln \left(\mathrm{C}_{\mathrm{HA}}\right)+0.751 \ln \left(\mathrm{C}_{\text {PIIINP }}\right)+0.394 \ln \left(\mathrm{C}_{\text {TIMP1 }}\right)$. Three biomarkers (type IV collagen, M2BPGi and ELF score) were measured using stored blood samples. All collected blood samples were stored at $-30^{\circ} \mathrm{C}$ until analysis.

Parameters associated with HCC. The following parameters were analyzed to identify the factors associated with HCC: Sex, cirrhosis, age, type IV collagen, M2BPGi, FIB-4 index, ELF score, AST, ALT, $\gamma$-glutamyl transpeptidase, albumin, total bilirubin, prothrombin time, platelets, AFP and des- $\gamma$-carboxy prothrombin. For all patients, all parameters were assessed at baseline and PTW24. 


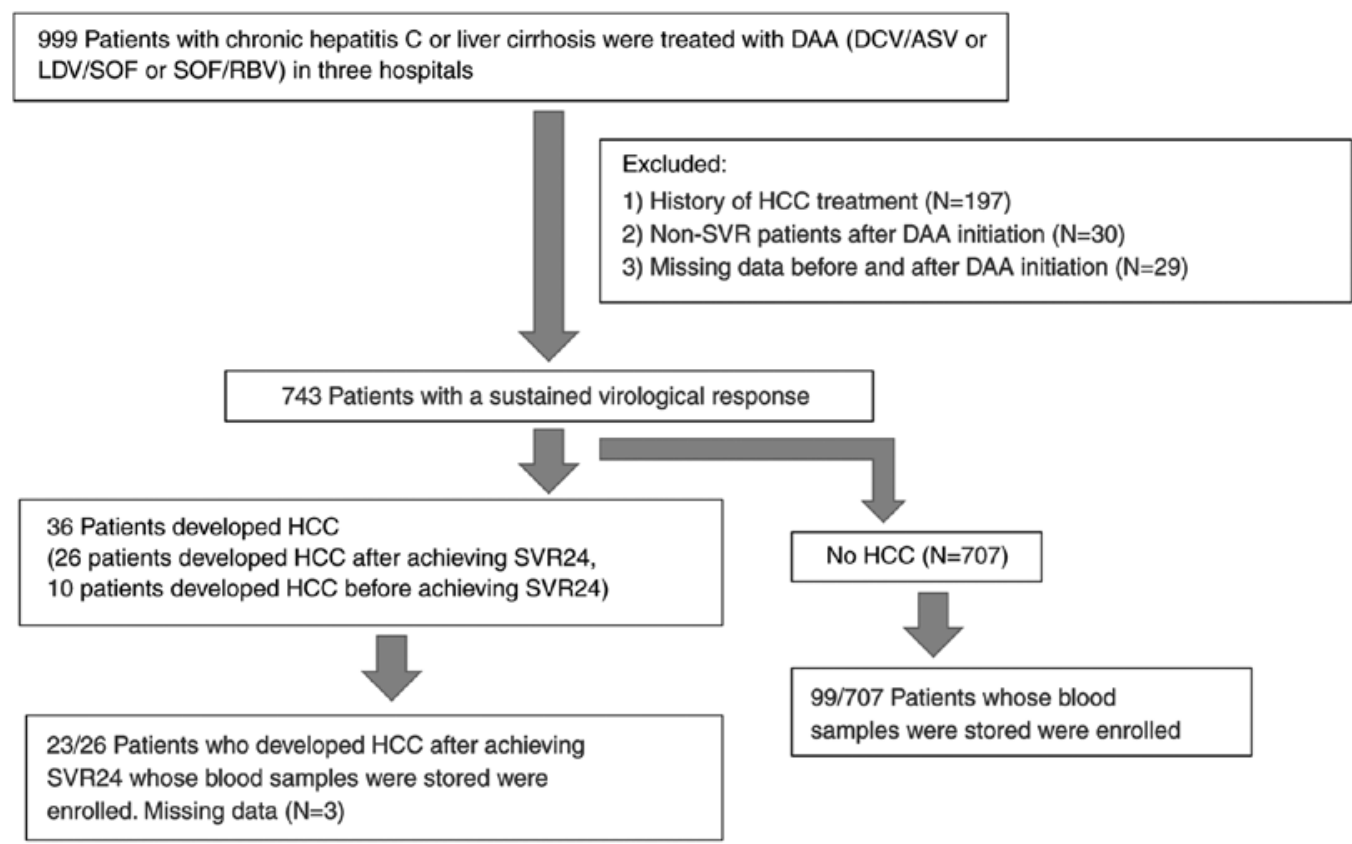

Figure 1. Flow chart of subject inclusion in the study. DAA, direct-acting antiviral; DCV, daclatasvir; ASV, asunaprevir; LDV, ledipasvir; SOF, sofosbuvir; RBV, bibavirin; HCC, hepatocellular carcinoma; SVR, sustained virological response; SVR24, SVR at 24 weeks.

Statistical analysis. Statistical analysis was performed using the JMP software package (release 13; SAS Institute, Inc.). Mean values and SDs were calculated for continuous data. For comparison of variables, the Wilcoxon signed-rank test was performed as appropriate. Factors associated with HCC risk were determined using the Cox proportional hazard regression analysis. $\mathrm{P}<0.05$ was considered to indicate statistically significant. Diagnostic accuracy was assessed using time-dependent receiver operating characteristics (ROC) curves by examining the area under the ROC curve (AUROC).

\section{Results}

Patient characteristics. The characteristics of the patients are summarized in Table I. Of the 122 patients, 50 (41\%) were male and $72(59 \%)$ were female, with a mean age of $68.7 \pm 8.8$ years. A total of $36(30 \%)$ patients were diagnosed with cirrhosis clinically.

Changes in fibrosis biomarkers and their association with HCC risk. The baseline/EOT/PTW24 fibrosis biomarkers (type IV collagen, M2BPGi, FIB-4 index and ELF score including its individual components, namely HA, PIIINP and TIMP-1) are shown in Table II. There was a significant decrease in all biomarkers at PTW24 compared with those at baseline $(\mathrm{P}<0.0001)$. First, the correlations among the four fibrosis markers were investigated. As a result, correlations were identified among the four fibrosis markers, albeit weak. The strongest correlation observed was between M2BPGi and type IV collagen $(\mathrm{r}=0.5998)$. A scatterplot matrix is shown in Fig. 2. Second, factors associated with the risk for HCC development were investigated (Table III). Of the 122 patients, 23 (19\%) developed HCC. A high baseline ELF score $(\mathrm{P}=0.0264)$, PTW24 ELF score $(\mathrm{P}=0.0003)$, baseline FIB-4 index $(\mathrm{P}=0.0451)$, $\mathrm{PTW} 24$ AFP level $(\mathrm{P}=0.0133)$, and baseline prothrombin time $(\mathrm{P}=0.0455)$ were identified as risk factors for HCC development based on the univariate analyses. A multivariate analysis was performed using the four factors that were found to be significant in the univariate analysis: PTW24 ELF score, baseline FIB-4 index, PTW24 AFP level and baseline prothrombin time. Based on the multivariate analysis, a high PTW24 ELF score was the only significant risk factor for $\mathrm{HCC}$ development $(\mathrm{P}=0.0035$; hazard ratio $=1.89$; $95 \%$ confidence interval: 1.24-2.85).

Diagnostic accuracy of fibrosis biomarkers for predicting HCC development. As the ELF score is composed of three fibrosis markers, it was examined which component was mostly involved. The diagnostic accuracy of the PTW24 ELF score, PTW24 HA, PTW24 PIIINP and PTW24 TIMP-1 for predicting HCC development is shown in Table IV. The cut-off value of the PTW24 ELF score of 10.96 had a sensitivity of $65.2 \%$ and specificity of $82.8 \%$ for predicting HCC development. PTW24 TIMP-1 had a high sensitivity (100\%) but low specificity (44.4\%). The AUROC of PTW24 ELF and PTW24 TIMP-1 was 0.75 and 0.76 , respectively. The ROC curves of PTW24 ELF, PTW24 HA, PTW24 PIIINP and PTW24 TIMP-1 are shown in Fig. 3.

\section{Discussion}

The objective of the present study was to measure fibrosis markers, tumor markers and biochemistry parameters in patients with chronic hepatitis $C$ who achieved SVR with DAA therapy in order to identify useful markers for predicting HCC development. The ELF score at 24 weeks after the completion of DAA therapy was demonstrated to be such a marker. In addition, the time course of the changes in fibrosis markers during DAA therapy was investigated, and the levels of all the markers decreased after the completion of therapy. 
Table II. Changes in biomarkers measured at baseline, end of treatment, and at 24 weeks after DAA therapy. P-values are for the comparison between baseline and 24 weeks after treatment.

\begin{tabular}{|c|c|c|c|c|}
\hline Biomarkers & Baseline & End of treatment & 24 weeks after treatment & P-value \\
\hline Type IV collagen (ng/ml) & $213 \pm 85$ & $190 \pm 67$ & $174 \pm 55$ & $<0.0001$ \\
\hline M2BPGi & $4.8 \pm 3.5$ & $2.7 \pm 2.0$ & $2.2 \pm 1.8$ & $<0.0001$ \\
\hline FIB-4 index & $5.31 \pm 3.82$ & $4.36 \pm 2.79$ & $4.24 \pm 3.09$ & $<0.0001$ \\
\hline ELF score & $11.5 \pm 1.2$ & $10.8 \pm 1.1$ & $10.4 \pm 1.0$ & $<0.0001$ \\
\hline $\mathrm{HA}(\mathrm{ng} / \mathrm{ml})$ & $534 \pm 780$ & $350 \pm 687$ & $224 \pm 272$ & $<0.0001$ \\
\hline PIIINP (ng/ml) & $15.3 \pm 7.7$ & $12.7 \pm 8.3$ & $10.6 \pm 5.3$ & $<0.0001$ \\
\hline TIMP-1 (ng/ml) & $338 \pm 291$ & $248 \pm 74$ & $233 \pm 69$ & $<0.0001$ \\
\hline
\end{tabular}

Values are presented as mean \pm SD. M2BPGi, Wisteria floribunda agglutinin-positive Mac-2-binding protein; ELF, enhanced liver fibrosis score; FIB-4, Fibrosis-4; HA, hyaluronic acid; PIIINP, amino-terminal propeptide of type-III procollagen; TIMP-1, tissue inhibitor of metalloproteinase type-1.

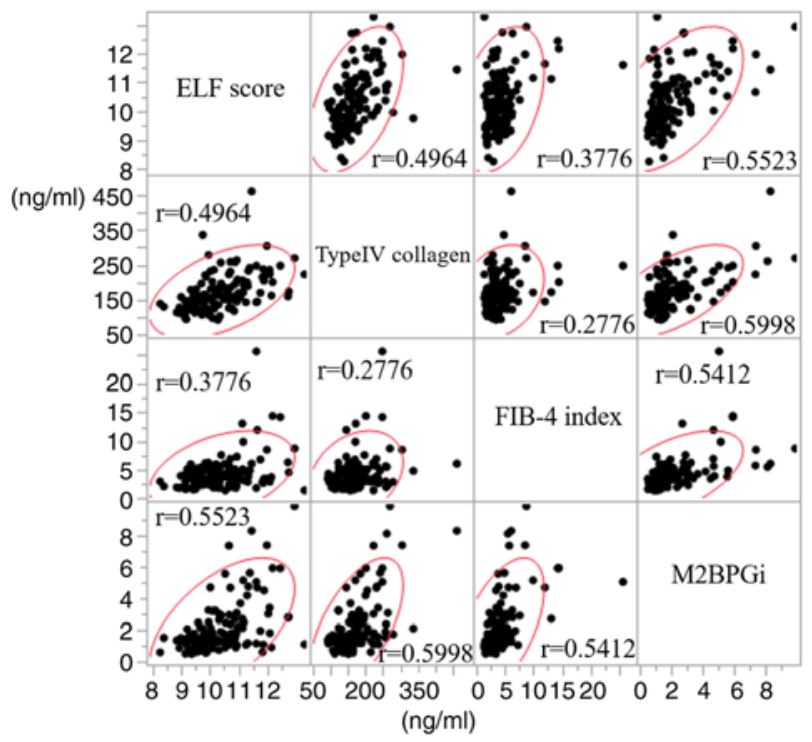

Figure 2. Scatterplot matrix of the correlations among the four fibrosis markers. The correlations among the four fibrosis markers were found to be weak. ELF, enhanced liver fibrosis; M2BPGi, Wisteria floribunda agglutinin-positive Mac-2-binding protein; FIB-4, Fibrosis-4.

As regards important markers for the prediction of $\mathrm{HCC}$ development after SVR, among fibrosis markers, M2BPGi (9) after the completion of DAA therapy was reported to be useful $(18,21)$. In addition, a pre-FIB-4 index of 3.25 was previously shown to exhibit a significant association with HCC development (19). In addition to fibrosis markers, the usefulness of AFP after treatment was also previously reported (20).

Therefore, M2BPGi, FIB-4 index and AFP, which were previously reported to be useful for predicting $\mathrm{HCC}$ development after SVR, were investigated in the present study. However, only the ELF score at 24 weeks after treatment was extracted by multivariate analysis and demonstrated to be the most useful marker for predicting HCC development.

The ELF score (12) is calculated from 3 hepatic fibrosis markers, HA, PIIINP, and TIMP-1, and these markers have been reported to be useful for evaluating fibrosis in varying etiologies of chronic liver disease such as non-alcoholic fatty liver disease (NAFLD), primary biliary cholangitis/cirrhosis and chronic hepatitis C (13-15). HA is a glycosaminoglycan involved in fibrogenesis by hepatic stellate cells, PIIINP is a marker of inflammation and early fibrogenesis, and TIMP-1 inhibits fibrinolysis, thereby increasing fiber deposition. The usefulness of HA, PIIINP and TIMP-1 as fibrosis markers in NAFLD was previously reported (22-24). Furthermore, HA, PIIINP and TIMP-1 have all been reported to be useful for the evaluation of fibrosis in chronic hepatitis C (25-27). Therefore, an increase in HA, PIIINP and TIMP-1 levels is considered to reflect fibrosis in NAFLD and chronic hepatitis C. Individual parameters may coincidentally increase due to the presence of other diseases; however, evaluation of liver fibrosis based on the ELF score is stable, as this score is calculated by summing up all three fibrosis markers (12). This may be the reason why only the ELF score was identified as the predictor of HCC development by multivariate analysis.

The longitudinal change in fibrosis markers during DAA therapy were next investigated, and all biomarkers were found to be significantly decreased 24 weeks after DAA therapy.

In patients who achieved SVR by DAA therapy, M2BPGi (28), ELF score (29) [and its components HA $(28,29)$ and TIMP-1 (29)],type IV collagen (28) and FIB-4 index (30-32) were found to be significantly decreased after therapy, consistent with the findings of the present study. In our study, PIIINP also significantly decreased after therapy. The decreases in the levels of these fibrosis markers may be due to the improvement of fibrosis. On the other hand, regarding the improvement of fibrosis stage based on histological examination of liver biopsy, it improves by 0.282 stages per year in patients who achieve SVR by IFN therapy (33), indicating that a long time is required for the improvement of liver fibrosis at the tissue level. The fibrosis markers investigated in the present study had decreased by $10-58 \%$ at 24 weeks after the end of therapy. The reduction rate in the levels of fibrosis markers from baseline to the end of therapy was higher compared with that from the end of therapy to 24 weeks after the end of therapy, suggesting that the decrease in fibrosis markers from baseline to the end of DAA therapy may reflect both inflammation and 
Table III. Factors associated with the risk for HCC development.

\begin{tabular}{|c|c|c|c|c|c|c|}
\hline \multirow[b]{2}{*}{ Factors } & \multirow[b]{2}{*}{$\mathrm{HCC}^{+}(\mathrm{n}=23)$} & \multirow[b]{2}{*}{$\mathrm{HCC}^{-}(\mathrm{n}=99)$} & \multicolumn{3}{|c|}{ Univariate analysis } & \multirow{2}{*}{$\frac{\text { Multivariate analysis }}{\text { P-value, HR, 95\% CI }}$} \\
\hline & & & HR & $95 \% \mathrm{CI}$ & P-value & \\
\hline Sex (male/female), $\mathrm{n}$ & $10 / 13$ & $40 / 59$ & 1.17 & $0.50-2.67$ & 0.707 & \\
\hline Liver cirrhosis/chronic hepatitis, $\mathrm{n}$ & $9 / 14$ & $27 / 72$ & 1.57 & $0.65-3.59$ & 0.299 & \\
\hline Age, years & $69.6 \pm 7.3$ & $68.5 \pm 9.0$ & 1.00 & $0.95-1.06$ & 0.915 & \\
\hline Pre AST (U/l) & $64.1 \pm 38.5$ & $50.9 \pm 22.7$ & 1.01 & $1.00-1.02$ & 0.070 & \\
\hline PTW24 AST (U/l) & $28.9 \pm 10.2$ & $26.9 \pm 9.0$ & 1.03 & $0.99-1.08$ & 0.153 & \\
\hline Pre ALT (U/l) & $61.3 \pm 49.8$ & $48.9 \pm 31.4$ & 1.01 & $1.00-1.01$ & 0.210 & \\
\hline PTW24 ALT (U/l) & $19.6 \pm 8.6$ & $19.6 \pm 11.5$ & 1.01 & $0.97-1.05$ & 0.581 & \\
\hline Pre $\gamma$-GTP $(\mathrm{U} / \mathrm{l})$ & $47 \pm 32$ & $40 \pm 40$ & 1.01 & $1.00-1.02$ & 0.100 & \\
\hline PTW24 $\gamma$-GTP (U/l) & $32 \pm 25$ & $26 \pm 27$ & 1.01 & $1.00-1.02$ & 0.155 & \\
\hline Pre Alb (g/dl) & $3.8 \pm 0.4$ & $4.0 \pm 0.4$ & 0.39 & $0.14-1.07$ & 0.067 & \\
\hline PTW24 Alb (g/dl) & $4.2 \pm 0.3$ & $4.3 \pm 0.3$ & 0.48 & $0.16-1.53$ & 0.210 & \\
\hline Pre T.Bil (mg/dl) & $0.9 \pm 0.3$ & $0.8 \pm 0.3$ & 1.34 & $0.33-4.50$ & 0.669 & \\
\hline PTW24 T.Bil (mg/dl) & $0.8 \pm 0.3$ & $0.9 \pm 0.3$ & 0.39 & $0.07-1.61$ & 0.215 & \\
\hline Pre $\mathrm{PT}^{\mathrm{a}}(\%)$ & $84.6 \pm 14.8$ & $92.5 \pm 15.6$ & 0.97 & $0.95-1.00$ & 0.0455 & \\
\hline PTW24 PT (\%) & $87.8 \pm 15.4$ & $92.4 \pm 13.9$ & 0.98 & $0.95-1.01$ & 0.217 & \\
\hline Pre Plt $\left(\mathrm{x} 10^{4} / \mu \mathrm{l}\right)$ & $11.2 \pm 5.2$ & $12.5 \pm 4.7$ & 0.95 & $0.86-1.04$ & 0.254 & \\
\hline PTW24 Plt $\left(\times 10^{4} / \mu 1\right)$ & $12.0 \pm 5.6$ & $13.1 \pm 4.3$ & 0.96 & $0.87-1.05$ & 0.388 & \\
\hline Pre AFP (ng/ml) & $23.7 \pm 39.4$ & $15.2 \pm 27.8$ & 1.00 & $0.99-1.01$ & 0.522 & \\
\hline PTW24 AFPa (ng/ml) & $8.1 \pm 11.0$ & $4.4 \pm 2.6$ & 1.06 & $1.02-1.09$ & 0.0133 & \\
\hline Pre DCP (mAU/ml) & $20.1 \pm 8.3$ & $20.5 \pm 19.6$ & 1.01 & $0.97-1.04$ & 0.457 & \\
\hline PTW24 DCP (mAU/ml) & $23 \pm 10$ & $21 \pm 16$ & 1.03 & $1.00-1.05$ & 0.0758 & \\
\hline Pre type IV (collagen (ng/ml) & $225 \pm 62$ & $210 \pm 89$ & 1.00 & $1.00-1.01$ & 0.522 & \\
\hline PTW24 type IV collagen (ng/ml) & $192 \pm 42$ & $169 \pm 56$ & 1.00 & $1.00-1.01$ & 0.120 & \\
\hline Pre M2BPGi & $5.43 \pm 3.02$ & $4.69 \pm 3.58$ & 1.05 & $0.93-1.16$ & 0.417 & \\
\hline PTW24 M2BPGi & $2.98 \pm 1.61$ & $2.05 \pm 1.76$ & 1.18 & $0.98-1.39$ & 0.0764 & \\
\hline Pre FIB-4 index ${ }^{\mathrm{a}}$ & $7.2 \pm 6.1$ & $4.9 \pm 2.9$ & 1.08 & $1.00-1.15$ & 0.0451 & \\
\hline PTW24 FIB-4 index & $5.6 \pm 5.0$ & $3.9 \pm 2.3$ & 1.09 & $0.99-1.17$ & 0.0879 & \\
\hline Pre ELF score & $12.0 \pm 1.1$ & $11.3 \pm 1.2$ & 1.47 & $1.05-2.10$ & 0.0264 & \\
\hline PTW24 ELF score ${ }^{a}$ & $11.2 \pm 1.0$ & $10.3 \pm 1.0$ & 1.96 & $1.38-2.77$ & 0.0003 & $\begin{array}{c}0.0035,1.89 \\
1.24-2.85\end{array}$ \\
\hline PTW24 HA (ng/ml) & $414 \pm 434$ & $180 \pm 193$ & 1.00 & $1.00-1.00$ & 0.0007 & \\
\hline PTW24 PIIINP (ng/ml) & $13.4 \pm 5.9$ & $10.0 \pm 5.0$ & 1.08 & $1.02-1.13$ & 0.009 & \\
\hline PTW24 TIMP-1 (ng/ml) & $277 \pm 63$ & $223 \pm 66$ & 1.01 & $1.00-1.01$ & 0.0033 & \\
\hline
\end{tabular}

${ }^{a}$ Multivariate analysis was performed using the four factors which were found to be significant in the univariate analysis: PTW24 ELF score, baseline FIB-4 index, PTW24 AFP level and baseline PT. Values are presented as mean \pm SD unless otherwise indicated. HCC, hepatocellular carcinoma; Pre, before treatment; PTW24, post-treatment week 24; AST, aspartate aminotransferase; ALT, alanine aminotransferase; GTP, glutamyl transpeptidase; Alb, albumin; T.Bil total bilirubin; PT, prothrombin time; Plt, platelet count; AFP, $\alpha$-fetoprotein; DCP, des- $\gamma$-carboxy prothrombin; ELF, enhanced liver fibrosis; M2BPGi, Wisteria floribunda agglutinin-positive Mac-2-binding protein; FIB-4, Fibrosis-4; HA, hyaluronic acid; PIIINP, amino-terminal propeptide of type-III procollagen; TIMP-1, tissue inhibitor of metalloproteinase type-1.

fibrosis in liver tissue. Indeed, in a previous study comparing the degree of liver fibrosis and fibrosis markers in patients with chronic hepatitis $\mathrm{C}$, the ELF score, M2BPGi and FIB4-index were considered to reflect both fibrosis and inflammation (34). These findings indicate that the fibrosis markers at PTW24 may reflect the fibrosis level with greater precision. Previous reports have demonstrated that hepatocarcinogenesis was closely associated with the degree of liver fibrosis rather than that of inflammation (35-37). Therefore, the ELF score at
PTW24 was selected as a predictor of HCC development after HCV eradication.

As regards the limitations of the present study, the total number of patients in the study was relatively small, but the HCC development rate was high (19\%). Age and cirrhosis were not found to be associated with HCC development, although these are known risk factors associated with the development of this type of cancer. In addition, a pre-FIB-4 index of 3.25 was previously found to exhibit a significant 
Table IV. Diagnostic accuracy of the PTW24 ELF score, PTW24 HA, PTW24 PIIINP and PTW24 TIMP-1 for predicting hepatocellular carcinoma development.

\begin{tabular}{lccccccr}
\hline Diagnostic measures & Cut-off & Sensitivity & Specificity & AUC & PPV & NPV & P-value \\
\hline PTW24 ELF score & 10.96 & 0.652 & 0.828 & 0.749 & 0.469 & 0.911 & 0.0002 \\
PTW24 HA $(\mathrm{ng} / \mathrm{ml})$ & 153.6 & 0.783 & 0.657 & 0.733 & 0.346 & 0.928 & 0.0009 \\
PTW24 PIIINP $(\mathrm{ng} / \mathrm{ml})$ & 10.5 & 0.783 & 0.687 & 0.717 & 0.367 & 0.932 & 0.0104 \\
PTW24 TIMP-1 $(\mathrm{ng} / \mathrm{ml})$ & 199.1 & 1 & 0.444 & 0.762 & 0.295 & 1 & 0.0013 \\
\hline
\end{tabular}

PTW24, post-treatment week 24; ELF, enhanced liver fibrosis; HA, hyaluronic acid; PIIINP, amino-terminal propeptide of type-III procollagen; TIMP-1, tissue inhibitor of metalloproteinase type-1; AUC, area under the receiver operating characteristic curve; PPV, positive predictive value; NPV, negative predictive value.
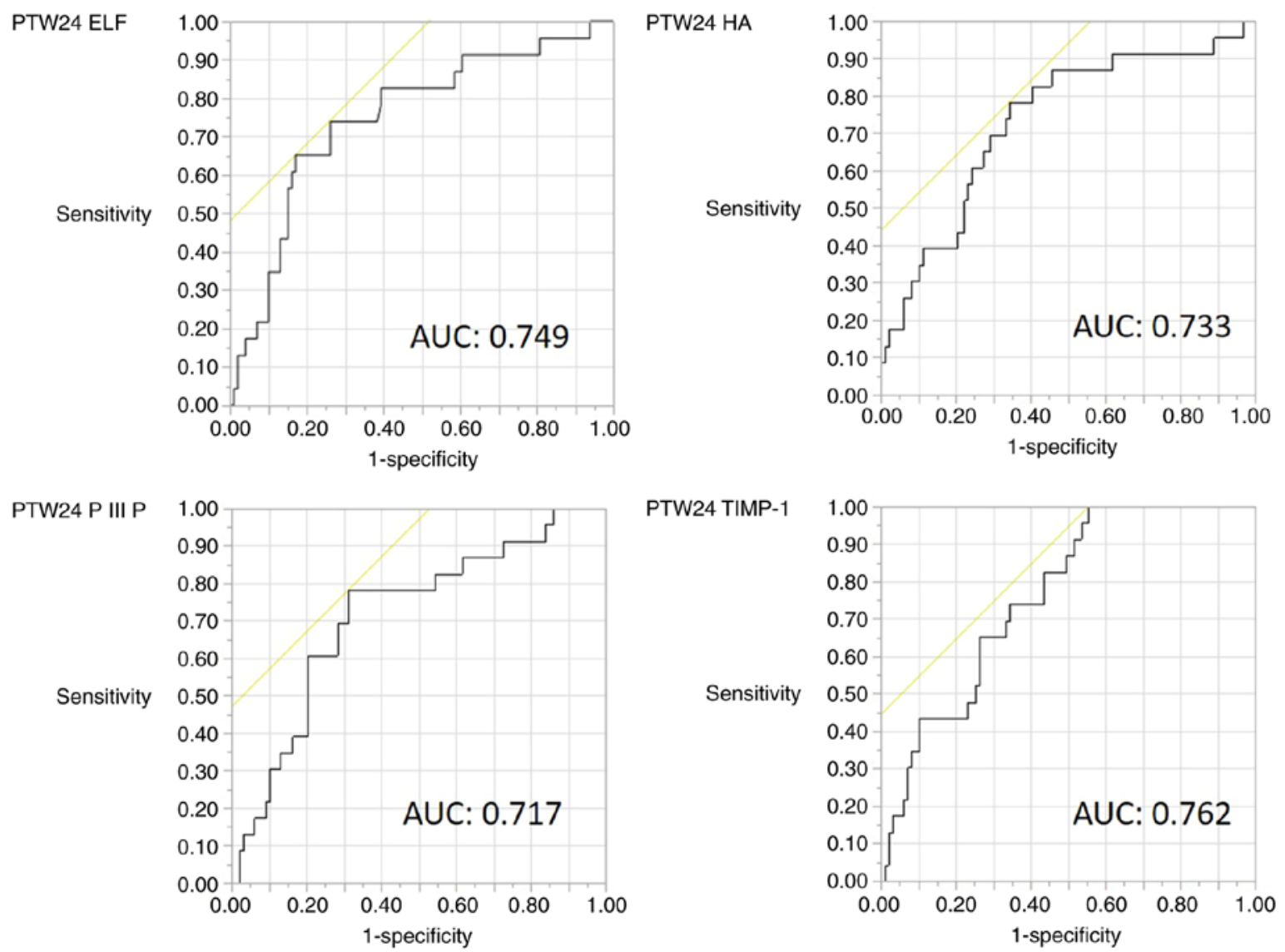

Figure 3. ROC curve of PTW24 ELF, PTW24 HA, PTW24 PIIINP and PTW24 TIMP-1 for prediction of hepatocellular carcinoma. AUC, area under the ROC curve; ROC, receiver operating characteristic; ELF, enhanced liver fibrosis; HA, hyaluronic acid; TIMP-1, tissue inhibitor of metalloproteinase type-1; PIIINP, amino-terminal propeptide of type-III procollagen; PTW24, post-treatment week 24.

association with HCC development (19). Finally, there may exist selection bias, as only patients with stored serum samples were selected.

In conclusion, the most useful parameter for predicting hepatocarcinogenesis after DAA therapy for chronic hepatitis $\mathrm{C}$ was found to be the ELF score at 24 weeks after therapy. In addition, the four investigated fibrosis markers decreased after DAA therapy. The number of patients who achieve SVR by DAA therapy is expected to increase in the future; therefore, the incidence of HCC development after SVR is also expected to increase. Although DAA administration improves inflammation and fibrosis, careful follow-up is required for patients with a high ELF score $\geq 10.96$ at 24 weeks after DAA therapy owing to the high risk for HCC development.

\section{Acknowledgements}

Not applicable.

\section{Funding}

No funding was received. 


\section{Availability of data and materials}

The datasets generated and/or analyzed during the present study are available from the corresponding author on reasonable request.

\section{Authors' contributions}

TK and TI contributed to the study concept and design; TK, TI, KA, TAH, RK, TS, SM, NO and TT contributed to data acquisition and analysis; TT revised the manuscript. TK and TI have seen and can confirm the authenticity of the raw data. All the authors have read and approved the final manuscript.

\section{Ethics approval and consent to participate}

The present study was reviewed and approved by the Ethics Committee of Kurume University School of Medicine (approval no. 14178), Yame General Hospital (approval no. 19-005), and Chikugo City Hospital (approval no. 2019-09). Written informed consent was obtained from all the patients enrolled in the study.

\section{Patient consent for publication}

Not applicable.

\section{Competing interests}

The authors declare that they have no competing interests.

\section{References}

1. Ji F, Wei B, Yeo YH, Ogawa E, Zou B, Stave CD, Li Z, Dang S, Furusyo N, Cheung RC and Nguyen MH: Systematic review with meta-analysis: Effectiveness and tolerability of interferon-free direct-acting antiviral regimens for chronic hepatitis $\mathrm{C}$ genotype 1 in routine clinical practice in Asia. Aliment Pharmacol Ther 47: 550-562, 2018.

2. Wei B, Ji F, Yeo YH, Ogawa E, Zou B, Stave CD, Dang S, Li Z, Furusyo N, Cheung RC and Nguyen MH: Real-world effectiveness of sofosbuvir plus ribavirin for chronic hepatitis $C$ genotype 2 in Asia: A systematic review and meta-analysis. BMJ Open Gastroenterol 5: e000207, 2018.

3. Mizokami M, Liu LJ, Fujiyama N, Littman M, Yuan J, Sekiya T, Hedskog C and Ng LJ: Real-world safety and effectiveness of ledipasvir/sofosbuvir for the treatment of chronic hepatitis $\mathrm{C}$ virus genotype 1 in Japan. J Viral Hepat 28: 129-141, 2021.

4. Calvaruso V, Cabibbo G, Cacciola I, Petta S, Madonia S, Bellia A, Tinè F, Distefano M, Licata A, Giannitrapani L, et al Incidence of hepatocellular carcinoma in patients With $\mathrm{HCV}$-associated cirrhosis treated with direct-acting antiviral agents. Gastroenterology 155: 411-421.e4, 2018.

5. Li DK, Ren Y, Fierer DS, Rutledge S, Shaikh OS, Lo Re V III, Simon T, Abou-Samra AB, Chung RT and Butt AA: The shortterm incidence of hepatocellular carcinoma is not increased after hepatitis $\mathrm{C}$ treatment with direct-acting antivirals: An ERCHIVES study. Hepatology 67: 2244-2253, 2018

6. Ioannou GN, Green PK and Berry K: HCV eradication induced by direct-acting antiviral agents reduces the risk of hepatocellular carcinoma. J Hepatol: Sep 5, 2017 (Epub ahead of print).

7. Kanwal F, Kramer J, Asch SM, Chayanupatkul M, Cao Y and El-Serag HB: Risk of hepatocellular cancer in HCV patients treated with direct-acting antiviral agents. Gastroenterology 153: 996-1005.e1, 2017.

8. Yabu K, Kiyosawa K, Mori H, Matsumoto A, Yoshizawa K, Tanaka E and Furuta S: Serum collagen type IV for the assessment of fibrosis and resistance to interferon therapy in chronic hepatitis C. Scand J Gastroenterol 29: 474-479, 1994.
9. Yamasaki K, Tateyama M, Abiru S, Komori A, Nagaoka S, Saeki A, Hashimoto S, Sasaki R, Bekki S, Kugiyama Y, et al: Elevated serum levels of Wisteria floribunda agglutinin-positive human Mac-2 binding protein predict the development of hepatocellular carcinoma in hepatitis C patients. Hepatology 60: 1563-1570, 2014

10. Vallet-Pichard A, Mallet V, Nalpas B, Verkarre V, Nalpas A, Dhalluin-Venier V, Fontaine $\mathrm{H}$ and Pol S: FIB-4: An inexpensive and accurate marker of fibrosis in HCV infection. Comparison with liver biopsy and fibrotest. Hepatology 46: 32-36, 2007.

11. Li X, Xu H and Gao P: Fibrosis index based on 4 factors (FIB-4) predicts liver cirrhosis and hepatocellular carcinoma in chronic hepatitis C virus (HCV) patients. Med Sci Monit 25: 7243-7250, 2019.

12. Rosenberg WM, Voelker M, Thiel R, Becka M, Burt A, Schuppan D, Hubscher S, Roskams T, Pinzani M and Arthur MJ; European Liver Fibrosis Group: Serum markers detect the presence of liver fibrosis: A cohort study. Gastroenterology 127: 1704-1713, 2004

13. Guha IN, Parkes J, Roderick P, Chattopadhyay D, Cross R, Harris S, Kaye P, Burt AD, Ryder SD, Aithal GP, et al: Noninvasive markers of fibrosis in nonalcoholic fatty liver disease: Validating the European liver fibrosis panel and exploring simple markers. Hepatology 47: 455-460, 2008.

14. Mayo MJ,Parkes J, Adams-Huet B, Combes B, Mills AS, Markin RS Rubin R, Wheeler D, Contos M, West AB, et al: Prediction of clinical outcomes in primary biliary cirrhosis by serum enhanced liver fibrosis assay. Hepatology 48: 1549-1557, 2008.

15. Parkes J, Guha IN, Roderick P, Harris S, Cross R, Manos MM, Irving W, Zaitoun A, Wheatley M, Ryder S and Rosenberg W: Enhanced liver fibrosis (ELF) test accurately identifies liver fibrosis in patients with chronic hepatitis C. J Viral Hepat 18: 23-31, 2011.

16. Omran D, Yosry A, Darweesh SK, Nabeel MM, El-Beshlawey M, Saif S, Fared A, Hassany M and Zayed RA: Enhanced liver fibrosis test using ELISA assay accurately discriminates advanced stage of liver fibrosis as determined by transient elastography fibroscan in treatment naïve chronic HCV patients. Clin Exp Med 18: 45-50, 2018.

17. Loo WM, Goh GB, Wang Y, Yuan JM, Ong L, Dan YY and Koh WP: Enhanced liver fibrosis score as a predictor of hepatocellular carcinoma. Clin Chem 64: 1404-1405, 2018.

18. Nagata H, Nakagawa M, Asahina Y, Sato A, Asano Y, Tsunoda T, Miyoshi M, Kaneko S, Otani S, Kawai-Kitahata F, et al: Effect of interferon-based and -free therapy on early occurrence and recurrence of hepatocellular carcinoma in chronic hepatitis $\mathrm{C}$. J Hepatol 67: 933-939, 2017.

19. Ioannou GN, Beste LA, Green PK, Singal AG, Tapper EB Waljee AK, Sterling RK, Feld JJ, Kaplan DE, Taddei TH and Berry K: Increased risk for hepatocellular carcinoma persists up to 10 years after $\mathrm{HCV}$ eradication in patients with baseline cirrhosis or high FIB-4 scores. Gastroenterology 157: 1264-1278.e4, 2019.

20. Asahina Y, Tsuchiya K, Nishimura T, Muraoka M, Suzuki Y, Tamaki N, Yasui Y, Hosokawa T, Ueda K, Nakanishi H, et al: $\alpha$-fetoprotein levels after interferon therapy and risk of hepatocarcinogenesis in chronic hepatitis C. Hepatology 58: 1253-1262, 2013.

21. Yasui Y, Kurosaki M, Komiyama Y, Takada H, Tamaki N, Watakabe K, Okada M, Wang W, Shimizu T, Kubota Y, et al: Wisteria floribunda agglutinin-positive Mac-2 binding protein predicts early occurrence of hepatocellular carcinoma after sustained virologic response by direct-acting antivirals for hepatitis C virus. Hepatol Res 48: 1131-1139, 2018.

22. Dvorak K, Stritesky J, Petrtyl J, Vitek L, Sroubkova R, Lenicek M, Smid V, Haluzik M and Bruha R: Use of non-invasive parameters of non-alcoholic steatohepatitis and liver fibrosis in daily practice-an exploratory case-control study. PLoS One 9: e111551, 2014.

23. Tanwar S, Trembling PM, Guha IN, Parkes J, Kaye P, Burt AD, Ryder SD, Aithal GP, Day CP and Rosenberg WM: Validation of terminal peptide of procollagen III for the detection and assessment of nonalcoholic steatohepatitis in patients with nonalcoholic fatty liver disease. Hepatology 57: 103-111, 2013.

24. Yilmaz Y and Eren F: Serum biomarkers of fibrosis and extracellular matrix remodeling in patients with nonalcoholic fatty liver disease: Association with liver histology. Eur J Gastroenterol Hepatol 31: 43-46, 2019.

25. McHutchison JG, Blatt LM, de Medina M, Craig JR, Conrad A, Schiff ER and Tong MJ: Measurement of serum hyaluronic acid in patients with chronic hepatitis $\mathrm{C}$ and its relationship to liver histology. Consensus interferon study group. J Gastroenterol Hepatol 15: 945-951, 2000. 
26. Leroy V, Monier F, Bottari S, Trocme C, Sturm N, Hilleret MN, Morel F and Zarski JP: Circulating matrix metalloproteinases 1, 2, 9 and their inhibitors TIMP-1 and TIMP-2 as serum markers of liver fibrosis in patients with chronic hepatitis C: Comparison with PIIINP and hyaluronic acid. Am J Gastroenterol 99: 271-279, 2004.

27. Boeker KH, Haberkorn CI, Michels D, Flemming P, Manns MP and Lichtinghagen R: Diagnostic potential of circulating TIMP-1 and MMP-2 as markers of liver fibrosis in patients with chronic hepatitis C. Clin Chim Acta 316: 71-81, 2002.

28. Miyaki E, Imamura M, Hiraga N, Murakami E, Kawaoka T, Tsuge M, Hiramatsu A, Kawakami Y, Aikata H, Hayes CN and Chayama K: Daclatasvir and asunaprevir treatment improves liver function parameters and reduces liver fibrosis markers in chronic hepatitis C patients. Hepatol Res 46: 758-764, 2016.

29. Bernuth S, Yagmur E, Schuppan D, Sprinzl MF, Zimmermann A, Schad A, Kittner JM, Weyer V, Knapstein J, Schattenberg JM, et al: Early changes in dynamic biomarkers of liver fibrosis in hepatitis $\mathrm{C}$ virus-infected patients treated with sofosbuvir. Dig Liver Dis 48: 291-297, 2016.

30. Yamazaki T, Joshita S, Umemura T, Usami Y, Sugiura A Fujimori N, Kimura T, Matsumoto A, Igarashi K, Ota M and Tanaka E: Changes in serum levels of autotaxin with direct-acting antiviral therapy in patients with chronic hepatitis C. PLoS One 13: e0195632, 2018.

31. Hsu WF, Lai HC, Su WP, Lin CH, Chuang PH, Chen SH, Chen HY, Wang HW, Huang GT and Peng CY: Rapid decline of noninvasive fibrosis index values in patients with hepatitis $\mathrm{C}$ receiving treatment with direct-acting antiviral agents. BMC Gastroenterol 19: 63, 2019.

32. Bachofner JA, Valli PV, Kröger A, Bergamin I, Künzler P, Baserga A, Braun D, Seifert B, Moncsek A, Fehr J, et al: Direct antiviral agent treatment of chronic hepatitis $\mathrm{C}$ results in rapid regression of transient elastography and fibrosis markers fibrosis-4 score and aspartate aminotransferase-platelet ratio index. Liver Int 37: 369-376, 2017.
33. Shiratori Y, Imazeki F, Moriyama M, Yano M, Arakawa Y, Yokosuka O, Kuroki T, Nishiguchi S, Sata M, Yamada G, et al: Histologic improvement of fibrosis in patients with hepatitis $\mathrm{C}$ who have sustained response to interferon therapy. Ann Intern Med 132: 517-524, 2000.

34. Fujita K, Kuroda N, Morishita A, Oura K, Tadokoro T, Nomura T, Yoneyama H, Arai T, Himoto T, Watanabe S and Masaki T: Fibrosis staging using direct serum biomarkers is influenced by hepatitis activity grading in hepatitis $\mathrm{C}$ virus infection. J Clin Med 7: 267, 2018.

35. Hiramatsu N, Oze T and Takehara T: Suppression of hepatocellular carcinoma development in hepatitis $C$ patients given interferon-based antiviral therapy. Hepatol Res 45: 152-161, 2015.

36. Motoyama H, Tamori A, Kubo S, Uchida-Kobayashi S, Takemura S, Tanaka S, Ohfuji S, Teranishi Y, Kozuka R, Kawamura E, et al: Stagnation of histopathological improvement is a predictor of hepatocellular carcinoma development after hepatitis C virus eradication. PLoS One 13: e0194163, 2018.

37. Yamaguchi $\mathrm{T}$, Matsuzaki K, Inokuchi R, Kawamura R, Yoshida K, Murata M, Fujisawa J, Fukushima N, Sata M, Kage M, et al: Phosphorylated Smad2 and Smad3 signaling: Shifting between tumor suppression and fibro-carcinogenesis in chronic hepatitis C. Hepatol Res 43: 1327-1342, 2013.

This work is licensed under a Creative Commons Attribution-NonCommercial-NoDerivatives 4.0 International (CC BY-NC-ND 4.0) License. 